\title{
Improving Motivation for Academics in Children with Autism
}

\author{
Lynn Kern Koegel • Anjileen K. Singh • \\ Robert L. Koegel
}

Published online: 10 March 2010

(C) The Author(s) 2010. This article is published with open access at Springerlink.com

\begin{abstract}
Many children with autism show very little interest in academic assignments and exhibit disruptive behavior when assignments are presented. Research indicates that incorporating specific motivational variables such as choice, interspersal of maintenance tasks, and natural reinforcers during intervention leads to improvements in core symptoms of autism and may possibly be effective in academic areas. Using a multiple baseline across children and behaviors design with four pre- and elementary school children with autism, we assessed whether the above variables could be incorporated into academic tasks to improve performance and interest. Results indicated that the intervention decreased the children's latency to begin academic tasks, improved their rate of performance and interest, and decreased their disruptive behavior. Theoretical and applied implications are discussed.
\end{abstract}

Keywords Academics - Motivation ·

Pivotal response treatment $\cdot$ Autism

\section{Introduction}

Children with autism spectrum disorders (ASD) and other disabilities are often exposed to academics and homework assignments that are challenging or simply uninteresting to

L. K. Koegel $(\varangle) \cdot$ A. K. Singh · R. L. Koegel

Counseling/Clinical/School Psychology Department, University

of California, Santa Barbara, CA 93106-9490, USA

e-mail: lynnk@education.ucsb.edu

L. K. Koegel · A. K. Singh · R. L. Koegel

Koegel Autism Center, University of California,

Santa Barbara, CA, USA the children. Research suggests that this may lead to mild to severe disruptive behavior used to avoid or escape the academic task (Ochs et al. 2001; Gunter et al. 1994).

Active participation in academics is important and children are expected to engage in and practice these fundamental skills both within and outside of the classroom. This is particularly important for children with ASD, as engaging in academics in the home setting provides opportunities to practice skills with one-on-one attention, thereby maximizing the likelihood of acquisition of targeted academics (Rosenberg 1989; Patton et al. 2001). In addition, the literature indicates that comprehensive and consistent programs across settings, involving school-home collaboration have the most successful outcomes (Harrower 1999; Harrower and Dunlap 2001; Baumgartner et al. 1993; Callahan et al. 2008). However, research has yet to clearly identify ways to motivate the children to engage in such broad academic participation.

A few studies, with populations other than autism, have suggested that antecedent interventions, such as including children's interests within academic assignments can decrease disruptive behavior and increase engagement and responsivity (Hinton and Kern 1999). Similarly, manipulating the consequences, so that academic activities result in natural reinforcers has been shown to improve academic engagement and decrease disruptive behavior (Kern et al. 1994). Preliminary literature suggests that some of these variables may also be effective with children with ASD (Dunlap 1984; Dunlap and Koegel 1980; Heimann et al. 1995; Koegel et al. 1994). As a package, the use of such variables has been effective for improving symptoms of autism, improving motivation for a variety of tasks, and decreasing disruptive behavior (Koegel et al. 1992, 1987).

The purpose of this study was to assess whether such motivational variables (choice, interspersal of maintenance 
tasks, and including natural reinforcers) could be employed to improve interest and performance in academic tasks. Specifically, we assessed whether these variables would improve writing and math performance, increase interest in the academic activities, and decrease disruptive behavior.

\section{Method}

\section{Participants}

Four children, from 4 to 7 years of age, participated in this study. All were diagnosed with autism by an outside state agency and exhibited symptoms of autism including delays in communication, difficulty with socialization, and restricted interests. Three of the four participants were fully-included and the fourth spent part of his day in regular education and part in a special education classroom for children with autism. All were selected for participation in this study due to parent report of significant difficulties with academics. Table 1 summarizes the age, gender, ethnicity, grade level, target academic tasks, and educational placement for each of the participants.

Robbie. Robbie's academic functioning was below grade level; but he was able to participate in the general education curriculum with modifications. However, when asked to engage in assignments, particularly involving writing or math, Robbie exhibited disruptive behavior such as crying, flopping on the floor, leaving the work area and hiding. In addition, his parents reported that his problem behaviors were escalating and he was having increasing difficulty with academic tasks.

Annie. Annie could read and write at grade level, but her performance was negatively affected by disruptive behavior such as refusing to engage in the academic task, crying, yelling, spitting, and kicking. Annie's parents reported that she was often isolated at school and home as a consequence of her aggressive behavior during academic tasks. Her parents also reported that her disruptive behavior during academic tasks was increasing.

Aidan. Aidan had a long history of disruptive behavior during academic tasks. His disruptive behavior included kicking, hitting, and lengthy tantrums when asked to engage in an academic task. In addition, his parents reported that the school had threatened expulsion due to his repeated aggression during academic tasks.

Mitchell. When presented with pre-academic writing and math tasks, Mitchell attempted to run away, hide, and throw materials. According to his parents, Mitchell rarely completed academic tasks and was showing increasing amounts of disruptive behavior during pre-academic tasks.

\section{Design}

A non-concurrent multiple baseline across participants and behaviors design was used to evaluate the effects of the intervention. Baseline sessions were systematically staggered across participants with 3, 5, 7, and 9 sessions, for Robbie, Annie, Aidan, and Mitchell, respectively.

\section{Procedure}

Prior to the start of the study, child-preferred reinforcers were identified based on observation and parent report. Sessions took place in the children's homes, and afterschool daycare program for Annie. During the sessions, writing and math tasks were presented following the protocol described in the independent variable section, below. Data were collected during each session and video probes were systematically collected biweekly throughout all conditions of the study for the purpose of calculating reliability.

\section{Independent Variable}

This study examined differences in child behaviors across baseline and intervention conditions for writing and math activities. In both conditions, the writing or math task was presented in the following format: The child was asked by an adult to engage in a math or writing task and told that child-preferred reinforcers could be earned contingent upon completion of the work. In both conditions, the task was provided at a fixed difficulty level and the numbers of problems/sentences presented to the child during each session were held constant. The writing tasks ranged from writing a single letter to writing multiple sentences. In the intervention condition the shorter writing tasks were interspersed with longer ones. The actual letter, word, or

Table 1 Participant characteristics

\begin{tabular}{llllll}
\hline & Age & Gender & Ethnicity & Target tasks & Educational placement \\
\hline Robbie & 5.1 & $\mathrm{M}$ & Latino & Addition, Subtraction, Writing & $1^{\text {st }}$ grade fully included \\
Annie & 7.8 & $\mathrm{~F}$ & European American & Writing & $1^{\text {st }}$ grade fully included w/FT aide \\
Aidan & 5.1 & $\mathrm{M}$ & Latino & Writing & KG fully included w/aide \\
Mitchell & 4.3 & $\mathrm{M}$ & Filipino/European American & Addition, Writing & Preschool combination of inclusion/special Ed. \\
\hline
\end{tabular}


sentence, was directly related to the natural reinforcer. Similarly for math, the tasks ranged from adding or subtracting single digit numbers (e.g. $2+3,7-5$ ) to double digit numbers (e.g. $24+57,75-45$ ). Easier math problems (e.g. $1+1)$ were interspersed with more difficult ones (e.g. $5+3$ ). Child specific interests were incorporated into the task, which allowed for a wider variety of tasks and same tasks were not presented repeatedly. Specific procedures are described below.

\section{Baseline}

During baseline, the adult presented a writing or math activity and asked the child to complete the task in order to earn a child-chosen reinforcer. The adult provided the materials for the task and chose the specific setting for the task (e.g. dining room table or desk). The reinforcer, although child-preferred, was not related to, or embedded within the task. For example, during a writing session, the adult may have told the child, "It's time to do some writing. Let's sit at the table." After sitting down the adult said, "Here's paper and a pencil. Write some sentences about your family. After you're done you can play outside." During math baseline, the adult said, "It's time to do some math. Let's sit down at your desk." Once the child was seated the adult said, "Here's paper and pencil, finish these problems. After you're done you can have a bowl of cheerios."

\section{Intervention}

During the intervention, the adult presented a writing or math activity and asked the child to complete the task in order to earn a child chosen reinforcer, as in the baseline condition. However, during intervention, motivational components were incorporated within the task. Specifically, the adult provided choices of the materials that could be used and the choice of the setting where the task could be carried out. In addition, the reinforcer was embedded within the task to provide a natural reward, and easy tasks were interspersed with the target tasks. For example, in the writing intervention, the adult said, "It's time to do some writing. Do you want to use a pencil or a marker?" After the materials were chosen, the adult asked, "Where would you like to sit?" Once the child was sitting where he or she wanted to, the adult said, "Write some sentences about playing outside. After you're done you can play outside." Another child was particularly fascinated by maps. He was asked to write the word "chalk" or "I want to draw a map" to be able to earn the chalk to draw maps of the city.

In math intervention, the adult said, "It's time to do math. What would you like to use, a crayon or a pen?" After the materials were chosen, the adult asked, "Do you want to sit at the table or on the floor?" Once seated, the adult continued, "Let's use your cheerios to do these problems. After you finish, you can eat the cheerios you added." Depending on the child's interests, the math task could use edibles such as gummy trains (if trains are the interest) or plastic pieces of a game that the child preferred to play. Consequently the task could be "Add $5+3$ with these gummy trains and you can eat the gummy trains" or "Subtract 3-2 with the ducks and then you can use the duck for your next turn (using the desired game)."

\section{Post-Intervention}

Post Intervention data were collected for all four participants during the post-intervention period, at least 2 weeks after intervention had been faded. During Post Intervention, four adults who were unfamiliar to the child and blind to the purpose of this study, were asked to engage the child in a math or writing activity. Data were collected on each of the four dependent variables.

\section{Dependent Measures}

Four dependent variables were used in this study, as follow.

\section{Latency}

Latency was defined as the number of minutes it took the child to begin the task once the adult had presented the instruction to do a writing or math assignment. Timing began immediately after instruction to complete the task was presented, and ended once the child began the activity as evidenced by engaging in the task, such as putting the pencil to paper and beginning to write or using fingers or other objects to count for math.

\section{Rate}

In order to obtain data on the child's productivity, the rate of assignment units completed was calculated based on the average number of letters written or math problems completed per minute.

\section{Disruptive Behavior}

Disruptive behavior was recorded using a continuous $30 \mathrm{~s}$ interval recording system. Disruptive behavior included crying, screaming, aggression such as kicking, hitting or spitting, refusal to respond, running away from the task, turning away from the task, or flopping onto the floor or other furniture. If the interval was characterized by one or more of the behaviors mentioned above, the interval was 
scored as disruptive. The number of intervals with disruptive behavior was divided by the total number of $30 \mathrm{~s}$ intervals to calculate an overall percentage of $30 \mathrm{~s}$ intervals in which the child engaged in disruptive behavior.

\section{Interest}

Interest was coded on a 5 point Likert scale adapted from Koegel and Egel (1979). The duration of the writing or math activity was broken down into $30 \mathrm{~s}$ intervals in order to code the level of interest shown by the child within each interval. For level of interest, observers' ratings in the $0-1$ range indicated low interest, ratings in the 2-3 range indicated neutral interest, and ratings in the 4-5 range indicated high interest (See Table 2). An average interest score was obtained for each probe by adding up the total interest scores and dividing by the total number of intervals.

\section{Reliability}

Two independent, B.A. level observers, naïve to the experimental hypothesis of the study, scored videotapes of the writing and math sessions and recorded data for all dependent measures for each child. Reliability was calculated for $40 \%$ of the sessions. Reliability was calculated using the standard formula, agreements divided by agreements plus disagreements multiplied by $100 \%$. Cohen's kappa was also calculated to correct for chance agreement on the categorical variables of disruptive behavior and interest. To control for observer drift, videotapes of the sessions were scored in random order.

For latency in both writing and math assignments, an agreement was defined as both observers recording the same latency (within $3 \mathrm{~s}$ ). A disagreement was defined as recording times that were more than $3 \mathrm{~s}$ apart. Mean percentage of agreement for latency was $98 \%$ in the writing condition (range $=75-100 \%$ ) and $100 \%$ in the math condition.
For rate (during both writing and math conditions), an agreement was defined as both observers recording the same number of letters written or math problems completed by the child, and recording the same duration of academic responding for the session following the latency period. A disagreement was defined as only one observer recording a letter written or math problem completed following the latency period. Mean percent of agreement for rate in the writing condition was $98 \%$ (range $=88-100 \%$ ) and $99 \%$ in the math condition (range $=89-100 \%$ ).

For disruptive behavior an agreement was defined as a $30 \mathrm{~s}$ interval in which both observers scored the interval as characterized by disruptive behavior. Mean percent of agreement for disruptive behavior for the writing activity was $95 \% \quad($ range $=77-100 \%)$ and 94\% (range $=$ $78-100 \%$ ) for the math activity. Kappa was calculated as .86 for recording disruptive for both the writing and math assignments.

For interest in both activities, an agreement was defined as a $30 \mathrm{~s}$ interval in which both observers recorded the same numerical interest rating. Mean percent of agreement for interest for the writing activities was 91\% (range = $75-100 \%$ ) and $80 \%$ (range $=73-100 \%$ ) for the math activities. Kappa for recording interest was .86 for the writing activities and .85 for the math activities.

\section{Results}

Data for latency are presented in Fig. 1. Data for writing are presented in the left panel and data for math are presented in the right panel. In all cases, the children's latency increased during baseline, consistent with parent report that the children were taking more and more time to start the writing or math task. However, immediately following implementation of the intervention latency decreased and remained low or absent throughout the intervention and post-intervention phases.

Table 2 Scale for rating child's interest, adapted from Koegel and Egel (1979)

\begin{tabular}{|c|c|c|}
\hline $\begin{array}{l}\text { Low } \\
\text { Interest } \\
(1-0)\end{array}$ & $\begin{array}{l}\text { (1): Child remains in the area of the activity but looks bored } \\
\text { and is uninvolved. The child may spend much time looking } \\
\text { around and little time attending to the task. The child may } \\
\text { engage in behaviors unrelated to the activity. }\end{array}$ & $\begin{array}{l}\text { (0): Child looks bored and attempts to leave the area of the } \\
\text { activity. Child may attempt to avoid or escape the task by } \\
\text { throwing tantrums, running away, whining, throwing } \\
\text { materials, crying, or refusing to perform the task. }\end{array}$ \\
\hline $\begin{array}{l}\text { Neutral } \\
\text { Interest } \\
(3-2)\end{array}$ & $\begin{array}{l}\text { (3): Child complies with the instruction, but does not appear } \\
\text { eager to participate in the activity. The child generally } \\
\text { focuses on the clinician and stimulus materials. }\end{array}$ & $\begin{array}{l}\text { (2): Child generally complies with the instructions, but } \\
\text { does not appear eager to participate. There may be } \\
\text { moments of staring or inattention, "toying with stimulus } \\
\text { materials" and being fidgety. }\end{array}$ \\
\hline $\begin{array}{l}\text { High } \\
\text { Interest } \\
(5-4)\end{array}$ & $\begin{array}{l}\text { (5): Attends readily to task; responds readily and willingly. } \\
\text { Child is alert, eager, and involved in activity. Child attends } \\
\text { to the clinician and/or the stimulus materials intently } \\
\text { during the trials. }\end{array}$ & $\begin{array}{l}\text { (4): Attends and responds to task readily. Child is fairly alert, } \\
\text { eager, and involved in the activity and frequently attends } \\
\text { to the clinician and/or stimulus materials during the trial. }\end{array}$ \\
\hline
\end{tabular}


Fig. 1 The latency, in terms of the number of minutes it took the child to begin the academic task after the adult's instruction are shown on the ordinate for each probe. Writing tasks are presented on the left panel and math tasks are presented on the right panel

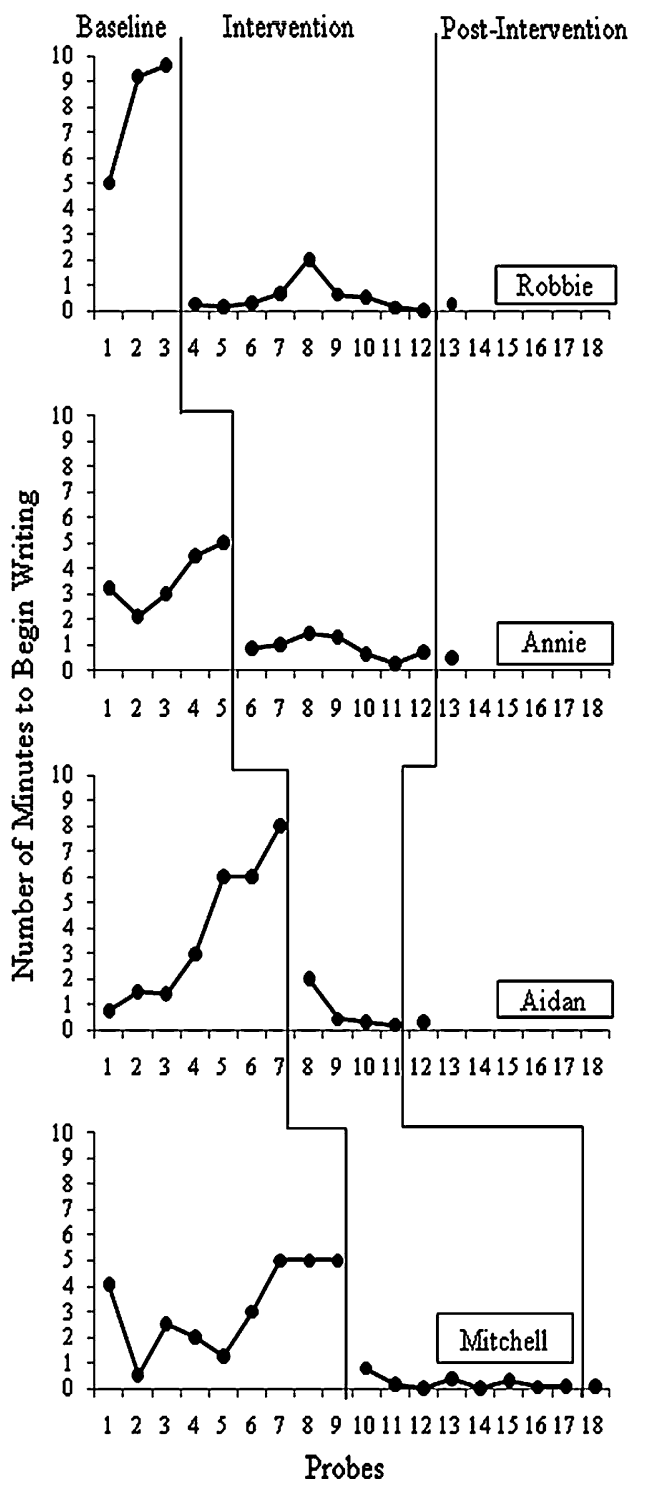

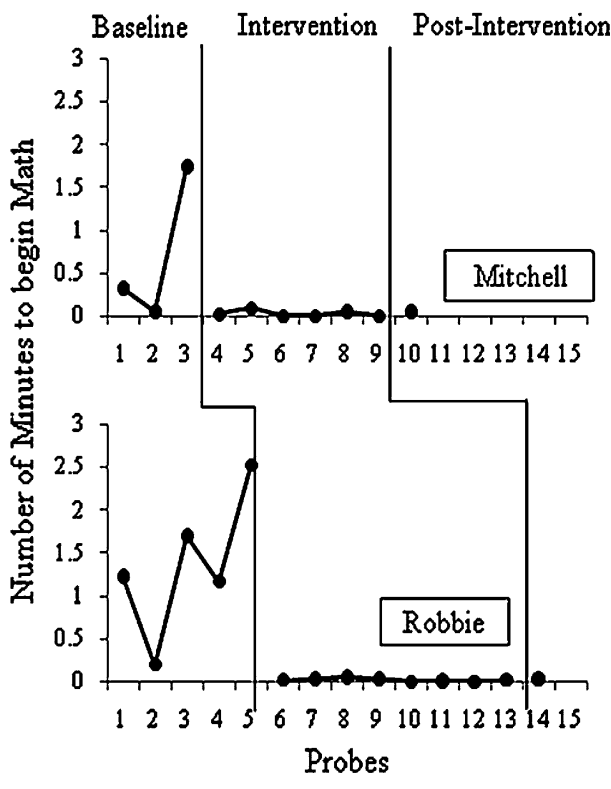

Specifically, during writing tasks Robbie's latency increased from 5 to $9.65 \mathrm{~min}$ in baseline. Immediately after the start of intervention his latency decreased to $16 \mathrm{~s}$ and, except for one probe, his latency remained at zero throughout the condition. Furthermore, Robbie began working on the task immediately following the instruction during the post-intervention probes, thus the latency was recorded as zero. Annie's latency increased from 3.25 to $6 \mathrm{~min}$ by the end of baseline. Once intervention was implemented, her latency decreased to $53 \mathrm{~s}$ and stayed low throughout intervention. At post-intervention Annie's latency had further decreased. Aidan's latency also increased during baseline from $45 \mathrm{~s}$ to 8 min. Immediately after the start of intervention, his latency decreased to $2.04 \mathrm{~min}$ and continued to decrease, reaching $12 \mathrm{~s}$ by the end of intervention. Mitchell's latency fluctuated between $30 \mathrm{~s}$ and $4 \mathrm{~min}$ during the beginning of baseline but remained consistent at $5 \mathrm{~min}$ by the end of baseline. Immediately following intervention, Mitchell's latency decreased to 1 min during the writing tasks. His latency continued to decrease throughout intervention and he was consistently starting his writing task almost immediately following the adult's instruction. This low latency maintained during the postintervention probe.

Similar trends occurred during the math activities. Both Robbie and Mitchell showed increases in latency during baseline. Mitchell's latency began at $20 \mathrm{~s}$ and increased to $1.75 \mathrm{~min}$ by the end of baseline. Following intervention, he was consistently beginning his math within $6 \mathrm{~s}$. Robbie's baseline latency began at $1.23 \mathrm{~min}$ and increased to $2.52 \mathrm{~min}$. His latency decreased to $1 \mathrm{~s}$ immediately following the start of intervention and remained low throughout intervention and at post-intervention. 
Data for rate of task completion are presented in Fig. 2. Data for writing are presented in the left panel and for math in the right panel. Consistent with parent report, each child showed low rates of task completion with three of the four children demonstrating decreasing trends during baseline. In all cases, the children's rate of writing and completing math problems increased immediately following implementation of the intervention and remained at high levels throughout the intervention and post-intervention phases.

Specifically, during baseline Robbie's rate of writing decreased from 1.86 letters per minute to 0 letters per minute. Immediately following the start of intervention, his rate of writing increased to 6 letters per minute and reached a high of 17.07 letters per minute near the end of intervention. This was a substantial improvement as was able to write 'I'm going to play some baseball at the park with dad' in intervention in approximately the same amount of time it took him to write 'ball' during baseline. Annie's rate of writing remained stable around 5 letters per minute throughout baseline. Following intervention, her rate of writing increased to $\mathbf{1 7 . 5 0}$ letters per minute and continued to improve throughout intervention. By post-intervention Annie was writing at an average rate of 23 letters per minute. Similarly, Aidan's rate of writing decreased steadily from an average of 10.50 letters per minute to 0 letters per minute by the end of baseline. Immediately following intervention, his rate of writing increased to an average of 14.38 letters per minute and stayed at similar levels throughout intervention and post-intervention. Mitchell's rate of writing in baseline decreased from an average of 2.58 letters per minute to 0 letters per minute. After the implementation of intervention, his rate increased to 14.80 letters per minute and remained high throughout intervention. Mitchell was able to write 'I love eating chocolate ice
Fig. 2 The rate of completion of writing (left panel) and math (right panel) for each participant. The total numbers of letters written or math problems completed are listed on the ordinate for each probe

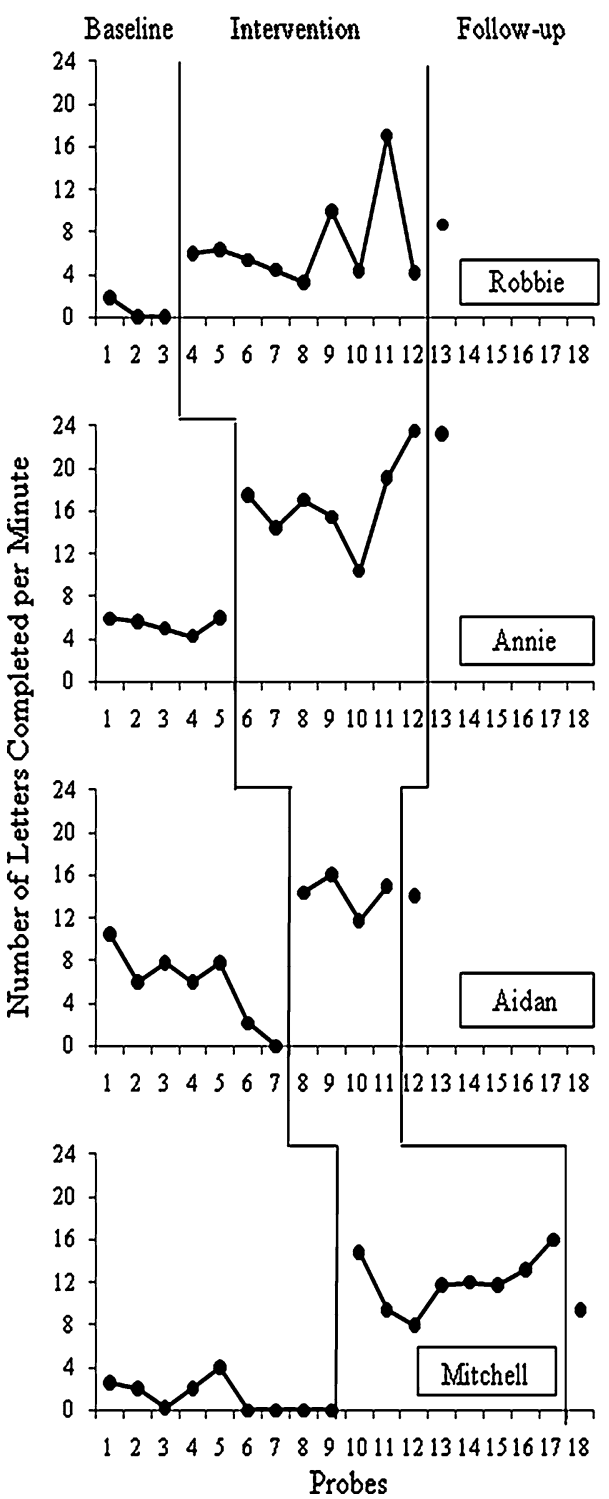


cream on hot days' in approximately the same amount of time it took him to write 'cream' during baseline.

Similar improvements were noted in math. During baseline, Mitchell completed zero to one math problem per minute. Following intervention, his math rate increased steadily from approximately two problems per minute to approximately nine math problems per minute by the end of intervention. Post-intervention, Mitchell completed an average of five math problems per minute. Robbie's rate of math completion decreased from an average of 0 to 1 math problems per minute during baseline. During intervention, his rate increased to an average of 3 math problems per minute by the end of intervention. Post-intervention data showed rates well above baseline for Mitchell and Robbie.

Data for disruptive behavior are presented in the left panel of Fig. 3 for writing and the right panel of Fig. 3 for math. Each child was showing increasing amounts of disruptive behavior during all academic tasks in baseline. For all children, disruptive behavior decreased immediately following implementation of the intervention and remained low throughout the intervention and post-intervention phases.

During baseline, Robbie consistently displayed disruptive behavior during $90-100 \%$ of the intervals during writing. Once intervention was implemented, Robbie's disruptive behavior decreased to $0 \%$ and remained at low levels throughout intervention. At post-intervention, Robbie demonstrated no disruptive behavior. Annie's disruptive behavior ranged from 65 to $100 \%$ during baseline. Immediately after intervention, the level dropped to $30 \%$ during the first intervention session and further dropped to $0 \%$ at the end of intervention. Low levels were also
Fig. 3 The percentage of $30 \mathrm{~s}$ intervals the participant engaged in disruptive behavior during writing (left panel) and math (right panel) on the ordinate

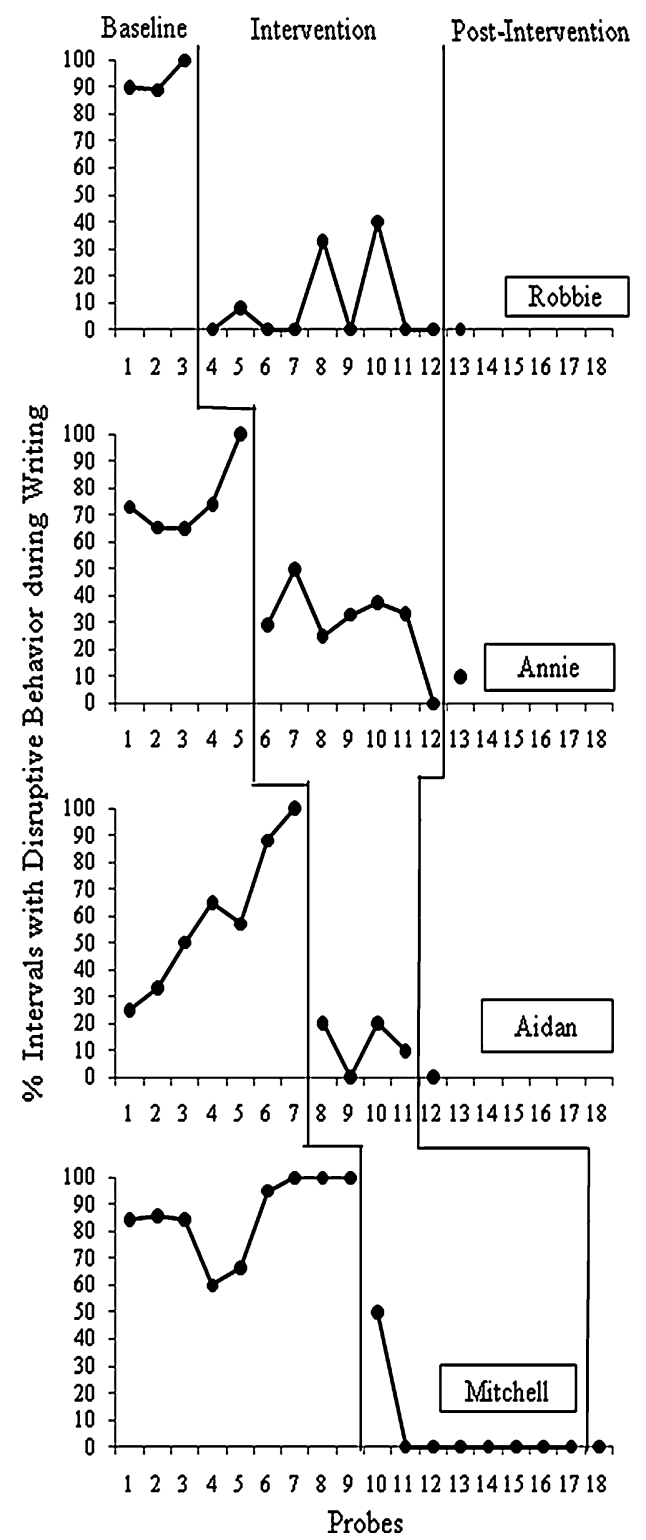


evidenced at post-intervention. Aidan's disruptive behavior increased steadily from 25 to $100 \%$ during the baseline sessions. His disruptive behavior ranged from 0 to $20 \%$ during intervention, and was at $0 \%$ during post-intervention. Mitchell's disruptive behavior ranged from 60 to $100 \%$ during baseline. Immediately after the start of intervention, Mitchell's disruptive behavior decreased to $50 \%$, then he exhibited no disruptive behavior during the remaining seven intervention probes, and no disruptive behavior was observed during the post-intervention condition.

Disruptive behavior during math activities also occurred at high levels in baseline and immediately decreased during intervention. Specifically, during baseline Mitchell's disruptive behavior ranged from 89 to $100 \%$ of the intervals and immediately decreased to $0 \%$ during intervention. His disruptive behavior remained at $0 \%$ during most of the intervention sessions and he displayed no disruptive behavior during post-intervention. Robbie's disruptive behavior ranged from 40 to $90 \%$ of the intervals during baseline. During intervention, his disruptive behavior decreased to $0 \%$ throughout most of the condition. He exhibited no disruptive behavior during post-intervention.

Data for interest are presented in Fig. 4. The levels of interest during writing are presented in the left panel and the levels of interest during math are presented in the right panel. The results for the interest measure paralleled the results for the other measures. That is, all four children showed low interest and often decreasing levels of interest during the baseline condition. In all cases, the children's interest increased immediately and reached high levels during the intervention and post-intervention phases. This pattern of improved interest following intervention was evident for both the writing and math activities.
Fig. 4 The interest ratings for writing (left panel) and math (right panel) for each participant. A rating of $0-1$ indicates low interest, 2-3 indicates neutral interest, and $4-5$ indicates high interest

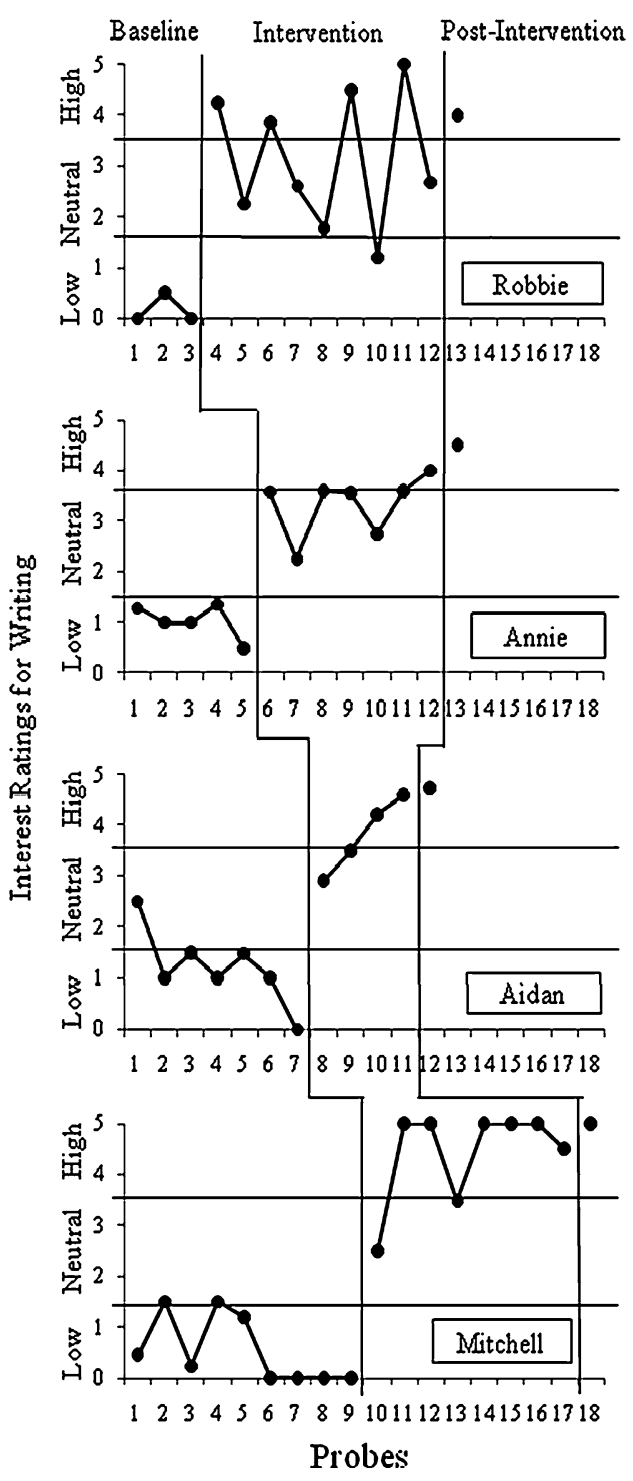




\section{Effect Size}

Effect size (Cohen's d) was calculated for all dependent measures for all children using the standard mean difference method (Busk and Serlin 1992). Using Cohen's (1988) standards, an effect size of 0.2 is indicative of a small effect, 0.5 a medium and 0.8 a large effect size. The results for all children on all academic tasks yielded large effect sizes.

Cohen's d for latency during writing showed a large effect size for all four participants (Robbie $d=2.89$, Annie $d=2.27$, Aidan $d=1.08$, and Mitchell $d=1.73$ ). In addition, there was a large effect size for rate of writing for all four participants (Robbie $\mathrm{d}=5.76$, Annie $\mathrm{d}=15.66$, Aidan, $\mathrm{d}=2.39$, and Mitchell $\mathrm{d}=7.27$ ). Similarly, for disruptive behavior a large effect size was found for all four children (Robbie $\mathrm{d}=13.82$, Annie $\mathrm{d}=3.14$, Aidan $\mathrm{d}=1.74$, and Mitchell $\mathrm{d}=5.43$ ). Finally, for interest, Cohen's d was also indicative of a large effect size (Robbie $d=10.17$, Annie $d=6.76$, Aidan $d=3.45$, and Mitchell $d=5.76$ ). Cohen's $d$ for latency during math showed a large effect size for Robbie $(\mathrm{d}=1.58)$ and a medium effect size for Mitchell $(\mathrm{d}=.75)$. A large effect size was found for rate of math completion (Robbie $d=3.81$ and Mitchell $d=9.72$ ) as well as disruptive behavior (Robbie $\mathrm{d}=2.59$ and Mitchell $\mathrm{d}=14.85$ ) and interest (Robbie $\mathrm{d}=7.71$ and Mitchell $\mathrm{d}=4.60$ ) for both children.

\section{Discussion}

The data from this study showed that incorporating motivational components in academic tasks resulted in faster completion rates, decreased disruptive behavior, and improved interest. These findings have both theoretical and applied implications. These results add to the existing literature by suggesting that not only did academic performance improve, but interest in academic learning improved as well. This is important for several reasons.

First, engagement and interest in academic tasks may create positive early learning experiences that influence children's future desire to continue learning (Bowman et al. 2001). Such positive early learning experiences may be especially important for children with ASD who tend to engage in disruptive behavior when academic tasks are presented (as the children may become more motivated to continue learning, as suggested by both the children's improved affect and by Robbie who, anecdotally was observed to repeatedly ask to do more math and writing tasks). This is consistent with the literature which suggests that early successes may provide a strong academic foundation, which in turn may allow children to learn more complex academic concepts (Bowman et al. 2001). More research in this area may be fruitful.

Related, disruptive behaviors are a major barrier to the acquisition of educational goals in children with autism (Koegel et al. 1987, 1992; Gunter et al. 1994). In this study, we found that the participants engaged in considerable disruptive behavior, thereby delaying the onset of the task and decreasing the number of tasks completed, even though the tasks were within their academic capability. However, by using the motivational variables, we were able to decrease or eliminate the disruptive behaviors as a collateral gain, without having to directly address the disruptive behaviors. The literature shows that disruptive behaviors are likely to worsen over time if left untreated (Horner et al. 2002). Thus, focusing on motivation appears to be a viable method of addressing problem behaviors without direct intervention. One advantage of using procedures that are directly incorporated into the curriculum is that they decrease the need for additional intervention programs targeting disruptive behaviors. For example, in a review of the literature Machalicek et al. (2007) found that most interventions to reduce challenging behaviors involve procedures that are implemented outside of the curricular content, such as self-management, social stories, videomodeling, cue cards, and so on. The implementation of these procedures requires additional student time for teaching and/or implementation, thereby reducing the amount of time the child is engaging in academics. Furthermore, manipulating variables that indirectly result in improvements in disruptive behavior decreases the need for punishment-based procedures, which can be demeaning, to control disruptive behavior (Carr et al. 1990).

Future research relating to individual child characteristics and the amount and duration of motivational procedures necessary to create interest in independent learning would be valuable. It is interesting to note that Robbie was observed to self-initiate games and activities involving writing which had never been observed prior to intervention. Initiations of such activities suggest that increased motivation and interest may lead children with ASD to seek out more opportunities for learning. This would be an interesting area for future research. In addition, research relating to child age and the point that is most critical and helpful for creating a positive learning foundation would be interesting. The youngest child in this study was 4 years old; however children begin learning at a much earlier age and may benefit from incorporating motivational components into teaching tasks at even younger ages (Bowman et al. 2001). Finally, research relating to the relationship between early positive academic experiences and the prevention of disruptive behavior, as well as the prevention of experiences of failure and resulting low levels of motivation, could be very valuable. At present, we are encouraged 
to see evidence that children with ASD can be motivated to engage in academic tasks with simultaneous improvements in interest.

Acknowledgments The authors would like to our express appreciation to Sarah Kuriakose, Elia Jimenez, Elizabeth Ponder, Cassidy Burton, Ashley Cardenas, and Camille Rozeira for their assistance with data collection and data analysis. This research and preparation of the manuscript were funded in part by NIH grant \#DC010924 and generous donations from the Kelly Family Foundation, the Eli and Edythe L. Broad Center for Asperger's Research, and the Kind World Foundation, but do not necessarily represent the opinions of the funders. We would also like to express our sincere appreciation to the families that participated in this research. Robert and Lynn Koegel are also partners in the private firm Koegel Autism Consultants.

Open Access This article is distributed under the terms of the Creative Commons Attribution Noncommercial License which permits any noncommercial use, distribution, and reproduction in any medium, provided the original author(s) and source are credited.

\section{References}

Baumgartner, D., Bryan, T., Donahue, M., \& Nelson, C. (1993). Thanks for asking: Parent comments about homework, tests, and grades. Exceptionality, 4, 177-185.

Bowman, B. T., Donovan, S., \& Burns, M. S. (2001). Eager to learn: Educating our preschoolers. Washington, DC: National Academy Press.

Busk, P. L., \& Serlin, R. C. (1992). Meta-analysis for single case research. In T. Kratochwill \& J. Levin (Eds.), Single-case research design and analysis: New directions for psychology and education (pp. 187-212). Hillsdale, NJ, England: Lawrence Erlbaum Associates, Inc.

Callahan, K., Henson, R. K., \& Cowan, A. K. (2008). Social validation of evidence-based practices in autism by parents, teachers and administrators. Journal of Autism and Developmental Disorders, 38, 678-692.

Carr, T., Ribinson, S., \& Palumbo, L. W. (1990). The wrong issue: Aversive versus nonaversive treatment. The right issue: Functional versus nonfunctional treatment. In A. C. Repp \& N. N. Singh (Eds.), Persepctives in the use of nonaversive and aversive interventions for persons with developmental disabilities (pp. 361-379). Sycamore, IL: Sycamore.

Cohen, J. (1988). Statistical power analysis for the behavioral sciences. Hillsdale, NJ: Lawrence Erlbaum Associates, Inc.

Dunlap, G. (1984). The influence of task variance and maintenance tasks on the learning and affect of autistic children. The Journal of Experimental Child Psychology, 37, 41-64.

Dunlap, G., \& Koegel, R. L. (1980). Motivating Autistic children through stimulus variation. Journal of Applied Behavior Analysis, 13, 619-627.
Gunter, P. L., Denny, R. K., Jack, S. L., Shores, R. E., \& Nelson, C. M. (1994). Aversive stimuli in academic interactions between students with serious emotional disturbance and their teachers. Behavioral Disorders, 18, 265-274.

Harrower, J. (1999). Educational inclusion of children with severe disabilities. Journal of Positive Behavior Intervention, 1, $215-230$

Harrower, J., \& Dunlap, G. (2001). Including children with autism in general education classrooms. Behavior Modifications, 25, $762-784$.

Heimann, M., Nelson, K. E., Tjus, T., \& Gillberg, C. (1995). Increasing reading and communication skills in children with autism through an interactive multimedia computer program. Journal of Autism and Developmental Disorders, 25, 459-480.

Hinton, L., \& Kern, L. (1999). Increasing homework completion by incorporating student interests. Journal of Positive Behavior Interventions, 1(4), 231-241.

Horner, R. H., Carr, E. G., Strain, P. S., Todd, A. W., \& Reed, H. K. (2002). Problem behavior interventions for young children with autism: A research synthesis. Journal of Autism and Developmental Disorders, 32(5), 423-444.

House, R. (2002). Loving to learn: Protecting a natural impulse in a technocratic world. Paths of learning: Options for families \& communities, 12, 32-36.

Kern, L., Childs, K., Dunlap, G., Clarke, S., \& Falk, G. (1994). Using assessment-based curricular intervention to improve the classroom behavior of a student with emotional and behavioral challenges. Journal of Applied Behavior Analysis, 27, 7-19.

Koegel, R. L., \& Egel, A. L. (1979). Motivating autistic children. Journal of Abnormal Psychology, 88, 418-426.

Koegel, R. L., O’Dell, M., \& Koegel, L. K. (1987). A natural language paradigm for nonverbal autistic children. Journal of Autism and Developmental Disorders, 17(2), 187-200.

Koegel, R. L., Koegel, L. K., \& Surratt, A. (1992). Language intervention and disruptive behavior in preschool children with autism. Journal of Autism and Developmental Disorders, 22(2), 141-153.

Koegel, R., Tran, Q., Mossman, A., \& Koegel, L. (1994). Incorporating motivational procedures to improve homework performance. In R. Koegel \& L. Koegel (Eds.), Pivotal response treatments for Autism (pp. 81-91). Baltimore, ML: Paul H. Brookes Publishing Co., Inc.

Machalicek, W., O'Reilly, M. F., Beretvas, M., Sigafoos, J., \& Lancioni, G. E. (2007). A review of interventions to reduce challenging behavior in school settings for students with autism spectrum disorders. Research in Autism Spectrum Disorders, 1, 229-246.

Ochs, E., Kremer-Sadlik, T., Solomon, O., \& Sirota, K. (2001). Inclusion as social practice: Views of children with autism. Social Development, 10(3), 399-419.

Patton, J. R., Jayanthi, M., \& Polloway, E. A. (2001). Home-school collaboration about homework: What do we know and what should we do? Reading and Writing Quarterly, 17, 227-242.

Rosenberg, M. S. (1989). The effects of daily homework assignments on the acquisition of basic skills by students with learning disabilities. Journal of Learning Disabilities, 22, 314-323. 